scalp, or with moist eczema behind the ears or in folds of the skin in other parts of the body.

But, while I would transfer the superficial varieties of lichen already described to eczema, it would be necessary to retain under this name at least three forms of the affection-namely, lichen marginatus, lichen planus, and lichen urticatus.

Lichen Marginatus entitles itself to special distinction by being in its essence a chronic inflammation of the follicles, and by its independence of other forms of eczema, although originating in the same way. It is a singular affection, and is evidently an exaggeration of lichen circinatus. It consists of rings having an inflamed and prominent margin, and ranging in size between a few lines and many inches in extent; the rings being sometimes numerous and dispersed, at other times solitary. It may be developed on any part of the body or limbs, but manifests a predilection for the region of the perinæum, often originating from the point of contact of the scrotum and thigh, and thence spreading upwards in front and behind, and giving rise to a series of remarkable curves upon the pubes, the groins, and the nates.

Lichen Planus is a chronic affection of the follicles, giving rise to papulæ peculiar in colour, configuration, and structure. The colour of the papule is a dull purplish or lilac red, and would seem to have sug. gested to Hebra the appellation "lichen ruber". The figure of the papule is flat, depressed on the summit, and quadrangular at the base. It is very slightly elevated. Its flattened summit is smooth and glistening, like horn, evidently from hypertrophy of the epidermis ; and it is umbilicated at the centre, where may be seen the aperture of a follicle filled with dry epithelial exuviæ. The eruption is discrete and disseminated at its first appearance, but is apt to concrete into blotches of considerable extent by the aggregation of its papulæ, and their blending by an infiltrated base. In this latter form, the horny coverings of the papulæ and the cuticle of the intervening congested skin exfoliate more or less abundantly, and, with the hard, dry, and greyish excreta of the follicles, give rise to an uneven desquamating surface, surmounting a red and thickened base. Lichen planus is frequently attended with intense and intermittent itching, and, on the subsidence of the papulæ and blotches, very commonly leaves behind it deeply pigmented maculæ.

Lichen Urticatus is an affection distinguished by the eruption of large scattered papulæ, of red colour, and attended with so much tingling and itching as to have suggested a comparison with urticaria; hence its name, lichen urticatus. It is an eruption of childhood, and has no relationship whatever with eczema, although included under the general denomination of eczematous affections. Its proper place very probably would be by the side of urticaria, and to that group it will doubtless be some day transferred.

Impetigo is the last of the examples of eczematous affections. It is a superficial pustule, an offshoot of eczema pustulosum, just as lichen, a pimple, is, as we have already seen, an offshoot of eczema papulosum. The study of eczema pustulosum has prepared us for an idiopathic eruption developing itself like an eczema, with a purulent or mucopurulent secretion; and such an affection we find illustrated in several of the models before us.

\section{OBSTETRIC MEMORANDA.}

\section{LABOUR INDUCED BY UTERINE INJECTION.}

THE case of Labour Induced by Uterine Injection, related by $\mathrm{Mr}$. Kemp in the JoURNAL of February I Ith, reminds me of an almost exactly similar one in my own practice.

E. W., a labourer's wife, a short square built woman, had had eight previous labours at full time, and on every occasion had been delivered by craniotomy - the children having been dead, owing to prolapsus of the cord, with the exception of the last, which was the first with which I attended her. In this case, as in Mr. Kemp's, there was no distortion of the pelvis; but its dimensions were abnormally narrow, so that the head of the child (a large one) stuck fast in the brim. Determined never again to run the risk of having to sacrifice a living child, I told her if ever she were in the family-way again, to give me an early notice, which in about a year she did. At the end of the eighth month of pregnancy, I injected a pint of warm water into the uterus by means of a large catheter and a syringe. As no action followed, I repeated the injection in twenty-four hours, using a pint and a half of water. This was at I I A.M. At 4 P.M., violent pains occurred in rapid succession, and in two hours the child was born, but dead - the presentation being normal. Although the douche acted sufficiently well in this case, I think that in another I should be disposed to try dilating the os uteri, as it seems to me probable that the child's death was due to the violence of the expulsive efforts of the uterus while the os was still closed.

H. Franklin Parsons, M.D.Lond.

\section{CLINICAL REMARKS ON THE}

\section{TREATMENT OF H EMOPTYSIS.}

\author{
By A. T. H. W A TERS, M.D., F.R.C.P.,
} Physician to the Liverpool Northern Hospital.

Gentlemen, - I wish to call your attention to the treatment of hæmoptysis. Cases of this affection are very frequently met with in our wards, and will often occur to you in your practice hereafter. There is scarcely any symptom which more alarms a patient, or a patient's friends, than the expectoration of blood; for people have a well-founded belief that it is a very common indication of the existence of pulmonary consumption. Indeed, setting aside those cases in which hæmoptysis is associated with heart-disease, or is of a vicarious character, in a very large proportion of the remainder it is undoubtedly connected with phthisis. I do not mean to say that hæmoptysis always indicates the presence of tubercles in the lungs, for I believe it may occur at a very early period of consumption, and before any tuberculous deposit has taken placein fact, that, at times, it is the first indication of phthisis, and may determine the development of that disease. The existence of hæmoptysis cannot prove to you that pulmonary consumption has arrived at any particular stage; for just as, I believe, it may take place before there is any tuberculous deposit, so it may occur when the disease is far advanced, and the lung full of cavities.

Considering the frequency of hæmoptysis, it is only in a small proportion of cases that it proves fatal-the patient dying suddenly from the profuseness of the hæmorrhage, and consequent suffocation, or sinking more or less rapidly from exhaustion. A case of rapid sinking occurred not long ago in my practice in the hospital, and I will briefly relate it to you.

H. G., aged 30, was admitted under my care on October I2th, 1869. He was brought from a vessel which had just arrived in the port, and was spitting up large quantities of blood. He was in a sinking state when admitted, and he died in about six hours. He had been under my care in the hospital three months previously. At that time there was dulness, with other signs of consolidation at the base of the left lung, and I considered the case to be either chronic pneumonia, likely to develope into phthisis, or phthisis beginning at the base. On making a post mortem examination, we found a large cavity at the base of the left lung, and a smaller one at the apex, and the substance of the lung was studded throughout with tubercles. The anterior part of the lung was emphysematous, and also contained tubercles. The right lung was more or less emphysematous throughout, and infiltrated with tubercles. In the middle lobe there was a large cavity filled with blood. A considerable quantity of blood was also found in the stomach. Here, then, we had a case in which ulceration or rupture of a large vessel on the walls of a cavity produced hæmorrhage so profuse as to cause rapid death.

This is the only case that has occurred in my practice in this hospital where hæmoptysis has been directly fatal ; but, curiously enough, within a short time-about ten days-of the death of my patient, my colleague, Dr. Glynn, lost a patient from pulmonary hæmorrhage, and, after death, a cavity was found in the left lung, into which blood had been poured in large quantity.

Whenever hæmoptysis is only slight, during the progress of a case of phthisis, no special treatment need be directed to it. It is better to continue the measures which you are adopting for the general treatment of the disease, and give encouragement to your patient if he be disposed to be alarmed at the appearance of a few specks of blood. But should the hæmorrhage be at all severe, you should at once enjoin rest, nor should you allow your patient to take exercise, or run any risk, by which an inflammatory attack might be brought on, until all appearances of blood have been lost for some days. I consider this rest and care most important, whether there have been no previous symptoms of phthisis and no other signs are present, or whether you have indications of existing deposit; and for this reason : that hæmoptysis is not infrequently followed by pneumonia, especially where the hæmorrhage has been severe. When blood is poured out into the lungs, unless it be all expectorated, it must necessarily act as an irritant, and inflammation is liable to be set up around it. This inflammation is often of a limited character; but, in two instances which have oc- 
curred to me within a somewhat recent period, extensive pneumonia followed hæmoptysis. It is true that in both these cases the hæmorrhage was copious, and in one which I shall relate to you a very large quantity of blood was lost.

I would caution you, therefore, to be on your guard, in all cases where hæmoptysis is at all severe, against the occurrence of pneumonia. It is better, I think, to err on the side of keeping the patient quiet, than to allow him to incur risk by too early exercise or exposure. The pneumonia which may result from a pulmonary hæmorrhage may determine the development of phthisis, which might possibly, by the exercise of proper care, have been prevented from becoming developed.

There is a kind of hæmoptysis which I have met with which is, I believe, the result of a simple oozing of blood from the mucous membrane of the bronchial tubes. The blood is not mixed with viscid sputa, nor is it pure blood; but the expectoration has very much the appearance of currant-juice. I have lately had a patient in whom this kind of expectoration had existed for a considerable time, and in whom, at the time he first came to me, I could discover no physical signs of consolidation of either lung. He had taken various medicines for the hæmorrhage, but nothing had done much good. I did not for some time adopt any special treatment for the bleeding, but confined myself to the administration of tonics, quinine, iron, and cod-liver oil. But, finding that the symptom did not cease, I ordered gallic acid in tengrain doses three times a day. This had the desired effect, and soon the hæmorrhage stopped. It has recurred at intervals, but the patient is able to check it by resorting to the gallic acid. Since I first saw the case, twelve months ago, symptoms of deposit in the right lung have supervened.

I will now call your attention to one of the most severe cases of hæmoptysis which I have ever seen. It will serve to illustrate the principles of practice which should be adopted in the treatment of this affection.

H. B., a German, 28 years of age, described as a merchant, was admitted into the hospital under my care on the 18 th September, 1868. He had just come by sea from Hamburg, and had suffered much from sea-sickness in consequence of rough weather. He told us that a year previously he had expectorated some blood, and that subsequently his health had been pretty good. I saw him soon after his admission. He was coughing up blood of a bright red colour, and in considerable quantities. His pulse was quiet, but he appeared very weak. I ordered him three grains of acetate of lead, with half a grain of opium, every four hours. I directed that he should be kept perfectly quiet, and have nothing in the way of food, but small quantities of iced milk or beeftea. I saw him on the evening of the following day. He had passed a bad night; the hæmorrhage had been very profuse; the blood was almost pure, and, although I did not measure it, I am sure that many ounces had been brought up. It was kept in several vessels, and one might have thought that a series of small venesections had been practised. The pulse was 90 , and the patient had taken his food pretty well. I ordered the pills to be given every two hours, and ice to be applied to the chest. On the 2oth, the quantity of blood expectorated was about the same as before, but the pulse had risen to Ioo. The patient was getting drowsy, and the pupils were contracted. I therefore stopped the opium, but continued the acetate of lead, and orderec dry cupping between the shoulders. I carefully examined the chest, but could find no marked physical signs of phthisis. There was, however, slight dulness, with deficient movement at the right apex. The heart sounds were normal. On the following day, there was a slight decrease in the hæmorrhage, but still the blood was in large quantities, quite fluid and florid; the narcotism had passed off, and the pulse had fallen a little. I consider that there was a slight improvement in the patient, but that the remedies were not acting quite satisfactorily, and that, unless the hæmorrhage were soon checked, the patient would sink from exhaustion. I had given a fair trial to the acetate of lead. It had been taken for three days in frequent doses with very little effect, and I felt that some other measures should be used. therefore ordered ten grains of gallic acid every two hours; the ice to be continued to the chest, and as much nourishment, in the shape of milk, beef-tea, and eggs, to be given as could be borne. The effect of the acid was very marked. On the 22nd, when I saw the patient, after he had taken the acid for twenty-four hours, he was spitting up only little masses of blood, and the quantity was largely diminished. On the following day, the improvement was still more marked, and I ordered the mixture to be taken every three hours only. On the 24th, the hæmorrhage was very slight, and the pulse had fallen to 84 . The gallic acid was now ordered to be taken every four hours; and on the 27 th, he was perfectly free from hæmoptysis, and, in fact, convalescent from his attack. But now mark what followed. On the 29th, he began to get worse; the pulse rose; he became feverish; and, in fact, an attack of pneumonia of the base of the left lung set in. As I propose to refer in a special lecture to this attack of the patient, I shall say no more than that he made a good recovery from it, and was discharged from the hospital on the 23rd October.

There was a very interesting case of hæmoptysis in the wards a shor time ago, to which I should like to call attention.

D. C. was admitted into the hospital on the 3 Ist of January, 1870 . He was 35 years of age, a cab-driver, and consequently had been much exposed to the weather; moreover, he confessed to being a free spiritdrinker. He had been in the habit, for some years, of taking five or six glasses of spirits a day. He told us that he had suffered from a cough for about two months, but that up to three days before his admission, he had brought up nothing but phlegm. On the evening of January 28th, he coughed up, he said, about half a pint of blood; on the following day, about a pint ; and, again, on the 3oth, about a pint. I saw him soon after he came to the hospital. The hæmorrhage had ceased, the respiration was not hurried, and the pulse was quiet. I did not examine the chest carefully, as I did not wish to disturb him for fear of reproducing the hæmoptysis ; but, from the slight examination I made, I could detect no organic disease. The man had a large pupil, a somewhat strumous aspect, and there was a flush on each cheek. The urine, on examination, was found healthy. I ordered acetate of lead and opium, and ice to the chest. For two or three days after his admission, he spat blood in small quantities; and, on the 5 th and 6th of February, there was no hæmorrhage at all ; but on the 8th it returned somewhat profusely. I at once ordered him ten grains of gallic acid every four hours, and, as the hæmorrhage had not quite ceased on the Ioth, the medicine was given every three hours. A careful examination of the chest on that day revealed no signs of organic disease. There was good resonance on both sides, and the expansion was good. The heart sounds were normal.

For three days the man was free from hæmoptysis, and I reduced the quantity of gallic acid; but on the night of the $13^{\text {th }}$ February, after reading aloud, he spat up about half a cupful of pure blood. Early on the morning of the 16 th, he awoke and coughed up about six ounces of blood. He continued to spit up small quantities of blood till the Igth, when there was no hæmoptysis, and the mixture was stopped ; but on the following day the hæmorrhage recurred to the extent of about half an ounce, and for several mornings he brought up about the same quantity. On the 24th, about II.20 A.M., he spat up about six ounces of bright arterial blood. The gallic acid was then resumed every two hours, and ice was applied to the chest. The pulse, which had been quiet, became more frequent, 108, but it soon fell. The hæmorrhage continued to a slight extent till the 27 th, when it ceased, but it recurred on the $4^{\text {th }}$ of March to the extent of a cupful of blood. I then added twenty minims of tincture of ergot to each dose of the gallic acid. From this time the hæmorrhage gradually became less and less, and at last ceased. On the 1 th he was put on tincture of iron. He had already taken cod-liver oil for about a fortnight. There was no more hæmorrhage until the 3oth March, on which day he brought up a little blood. I again ordered the gallic acid, and the bleeding was soon stopped. He left the hospital on the 7th April.

I made a careful examination of the chest on several occasions, and once just before the patient was discharged, but I could find no evidence of deposit in either lung, and if any existed it must have been deep-seated.

And now I will call your attention to the various measures which are usually resorted to in the treatment of hæmoptysis. In the first place, I believe that the best remedy you can use, the safest, the most rapid, and the most effectual, is gallic acid. It must be given in full dosesnot less than ten grains every hour, or every two, three, or four hours, according to the severity of the case. It is readily taken by patients; it rarely disagrees with the stomach, and is well borne by delicate persons. I have now used it in a large number of cases, and I can speak with confidence of its value. I have rarely found it fail, but still it has not been invariably successful in rapidly checking the hæmorrhage. You may recollect the case of Peter $\mathrm{R}-$, who was so long in the house, and in whom hæmoptysis recurred over and over again. I prescribed a variety of remedies for this man, and each in its turn failed to arrest the bleeding. It is quite true, however, that gallic acid answered better than any other agent used; it never failed to diminish the quantity of blood expectorated, and on several occasions it stopped the hæmoptysis altogether for a time, and this is more than I can say of either of the other substances used. I do not think you gain anything by giving the acid in larger doses than ten grains; but I know that some physicians give it in twenty-grain doses. It rapidly finds its way into the urine and is excreted.

Acetate of lead is another valuable preparation for arresting hæmoptysis : combined with opium it is often of great service. I usually give 
it in the form of pill in two- or three-grain doses every two, three, or four hours. I have seen very severe cases yield to this treatment. Some of you may recollect one of our house-surgeons who had a bad attack of hæmoptysis, and for whom I prescribed this substance, and who made a satisfactory recovery.

In the opinion of some physicians, acetate of lead is a more powerful styptic than gallic acid, but in the treatment of the form of hæmorrhage which we are now considering I prefer the latter; if, however, in any case this failed, I should resort to the lead preparation. If you give it, it must be in the full doses which $I$ have recommended.

Sulphuric acid is a good remedy in slight cases of hremoptysis; and it may be combined with other substances, as quinine, iron, etc., which are given for the general treatment of the disease; and, indeed, I have seen cases which have been somewhat severe yield to full doses of this acid. There was a man in the wards some years ago who was spitting a good deal of blood, and for whom the house-surgeon had ordered sulphuric acid in ten-minim doses. I saw the patient for the first time after he had been taking the acid for two or three days, but it had not checked the hæmorrhage in the slightest degree. I considered the dose too small, and I increased it to thirty minims. In twenty-four hours the hæmorrhage had greatly diminished, and it soon stopped. If you are disposed to try this acid in any severe case, you must give it in full doses ; but it is not so easily taken, nor is it so well borne by patients as gallic acid. Moreover, as it must be largely diluted to be taken, it necessitates the swallowing of a good deal of liquid, which is generally o be avoided.

Let me give you a caution in reference to the administration of opium. It is well to bear in mind its tendency to confine the bowels; for, in treating persons who are very weak for hæmoptysis, you may find that when you have checked the hæmorrhage you have great trouble in getting the bowels opened, and the efforts to move them may reproduce the bleeding. Of course, in any severe case you must do all you can to stop the hæmorrhage, and opium, either with gallic acid or acetate of lead, is often, I think, useful. It doubtless possesses some styptic powers, and, moreover, is probably of use in sustaining the patient under the influence of the loss of blood. I advise you, however, not to continue its use longer than is absolutely necessary.

My experience of the use of ergot of rye in pulmonary hæmorrhage is not very favourable. I have given the tincture in several cases, but I have not been very satisfied with the results. It may be applicable to some cases, but I do not think that it possesses such valuable properties as gallic acid or acetate of lead.

In severe cases of hæmoptysis, I always apply ice to the chest. We know that a cold substance applied to the skin will produce a reflex contraction of distant blood-vessels ; and it has appeared to me that ice applied to the chest has been of service in checking hæmoptysis. I have never seen any injurious results follow its use. The ice should be applied in a bag, and should not be kept on sufficiently long to produce a chill.

You will find digitalis recommended by some writers as a valuable agent for checking hæmoptysis. I have frequently found, in cases to which $I$ have been called in consultation, that this medicine has been given, and I know that many practitioners have great confidence in it. They do not, however, prescribe it alone, but in combination with other remedies, as sulphuric acid and laudanum, so that it is difficult to say how far the results which have followed have been due to the digitalis itself. As far as my own experience goes-and I have frequently prescribed digitalis-I cannot recommend it as a trustworthy remedy in hæmoptysis. You are probably aware that there are conflicting views in reference to the action of digitalis. On the one hand, it has been considered a cardiac sedative; on the other, a cardiac tonic. If, as is alleged by some, it have the power of causing contraction of the smaller arteries, it ought to be, theoretically, useful in hæmoptysis ; but on this point I can only give you the result of own clinical observations, and, having tried it and found it fail, I have given up its use.

I occasionally prescribe dry cupping in hæmoptysis, especially if it be of an active character; but I never fail to give styptics internally at the same time.

With regard to the administration of purgatives, I must caution you against their indiscriminate use in this affection. When you have to deal with tolerably robust individuals you may safely give purgatives, and they will often be of service; but when the hæmorrhage is severe, or the patient in a very exhausted condition, you must be very careful how you further lower him by their administration. It becomes sometimes a very serious question whether the movements necessary for the action of the bowels may not prove injurious by opening a vessel which has recently closed. In some cases the thread on which life appears to hang seems so slight that we dare not allow the slightest movement on the part of the patient, and we are glad that the bowels remain inactive.
Whenever your patients show symptoms of exhaustion during the occurrence of hæmoptysis, you need not hesitate to give small doses of stimulants with food at regular intervals. I do not believe that such treatment in anywise tends to increase the hæmorrhage, and it has a beneficial effect in sustaining the patient.

There is one remedy to which I have not referred; viz., turpentine. It is most valuable in hæmorrhage from the bowels, but less so, in my opinion, in pulmonary hæmorrhage. However, it is an agent to which you may have recourse should other measures fail.

A few words as to the general management of your patient. Let him be kept perfectly quiet, and do not allow any person to be with him except his nurse. Take care that his room is kept cool and well ventilated, and give no other food than milk and beef-tea, in small quantities and iced. Thirst will often be complained of : this is best relieved by small lumps of ice. You must not allow large draughts of iced-water, and everything likely to cause vomiting or distension of the stomach must be specially avoided. Lastly, let me advise you not to disturb your patient for the purpose of making unnecessary physical examinations.

\section{RECOLLECTIONS OF WORK IN AN AMBULANCE.}

\section{By WILliAM MAC CORMAC, F.R.C.S.}

$$
\text { IX.-Conclusion. }
$$

PERHAPS I cannot do better in concluding what is but a sketch, and, I fear, a somewhat imperfect one, of our ambulance work, than by giving in extenso a table of all the cases of injury which we received and treated in Asfeld, and of all the operations that were performed. Some of these operations were, however, not performed at Asfeld, the patients having been sent to us subsequently from other ambulances. The classification of the injuries is made mainly according to regions from the head down to the foot, which is, perhaps, the simplest and the best plan. When the injuries have been multiple, they are classed under that one which is likely to prove most dangerous to life. Besides the cases thus recorded, there are a number whose names were never discovered, and all source of identification was lost. There are several, too, whose names are known, but not the forms of injury from which they suffered. All this was unavoidable. The amount of work imposed upon us was simply overwhelming for the first few days.

I have prepared these tables with a good deal of care and after a great deal of trouble. I had my own notes, and, in addition, a general register of all the cases. By collating these two carefully I think I have been able to exclude serious error, and to present as correct a resumé of our work in a tabular form as it is possible to have.

Table of Injuries Treated at Asfeld during Sept. and Oct. I870.

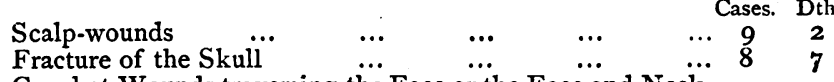

Gunshot Wounds traversing the Face or the Face and Neck,

and in general Fracturing the Bones ... ... 24

Wounds of the Face destroying an Eye $\quad \ldots .6424$

Wounds traversing the Neck ...

(In one case the trachea was divided).

Wounds of the Soft Parts around the Shoulder-joint with out Penetration of the Articulation

Wounds around the Elbow-joint without Penetration $\quad \ldots \quad 7$

Wounds of the Soft Parts of the Hip and the Buttock $\ldots$. I 8

Wound of the Buttock and other parts $\quad \ldots \quad \ldots 7$

Complete Avulsion of the Buttock, with Fracture of the Ilium and Sacrum $\ldots$... $\quad \ldots \quad \ldots \quad \ldots \quad 2$

Wounds around the Knee-joint not penetrating theArticulation $2 \mathrm{I}$

(In one case the Popliteal Artery was divided by the ball, causing Sphacelus.)

Wounds around the Ankle-joint without Penetration

Penetrating Wounds of the Shoulder-joint

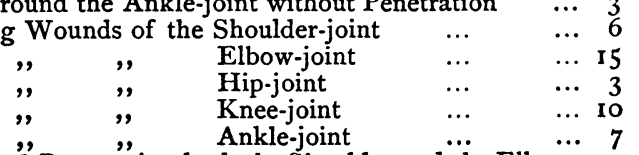

Shell-wound Penetrating both the Shoulder and the Elbow-

joint of the same Arm $\quad . . \quad \ldots . \quad \ldots \quad \ldots$

(1) 